\title{
Introdução e melhoramento de soja na várzea do rio Solimōes (Caldeirào, Cacau Pirera), no período de 1975 a $1976\left(^{*}\right)$
}

\author{
Fazal Rahman (**)
}

\begin{abstract}
Resumo
Nossos primeiros estudos indicaram que a produção de soja, em larga escala, nas áreas férteis nas várzeas do Amazonas, é possivel desde que se resolvam os problemas de secagem e armazenagem durante os períodos de chuva ou muito úmidos. De 15 variedades testadas neste experimento, 5 produziram mais de $2.000 \mathrm{~kg}$ por hectare. Júpiter produziu a maior quantidade de sementes, isto é $4.588 \mathrm{~kg}$ por hectare, seguida pela Williams, Hardee, Pelicano Melhorado e Semmes com, respectivamente, 2.628, 2.610,2.114, 2.053 kg de produção por hectare. Júpiter floresceu em 37 dias,, maturou em 116 dias, teve porte ereto, excelente nodulaçăo e qualidade de sementes. Suas sementes contiveram $43,6 \%$ de proteinna e $25,3 \%$ de óleo. Júpiter mostrou também uma grande resistência às doenças, sob as condições mais desfavoráveis, de excesso de chuva e umidade; suas sementes também mantiveram boa qualidade. Pelicano Melhorado também exibiu características semelhantes.
\end{abstract}

\section{INTRODUÇÃo}

A soja vem aumentando o seu papel na economia nacional e na nutrição humana e animal dia a dia. Isto é perfeitamente compreensivel, pois, as sementes de soja integral contêm uma média de $40 \%$ de proteína de alta qualidade e $21 \%$ de óleo.

A soja é rica em cálcio, fósforo, ferro e vitaminas como Tiamina, Riboflavina e Niacina (Cowan, 1973; Litzenberger, 1974). Cada 30 kg de soja produzem $18,5 \mathrm{~kg}$ de óleo e $78,9 \mathrm{~kg}$ de torta (Soybean Magic).

O valor total da colheita de soja americana foi estimado, em 1972, em 6 bilhões de dólares. O valor de exportação da soja para os Estados Unidos em 1971 alcançou 1,9 bilhões de dólares, ou seja, 1/4 de todas as exportaçöes agrícolas (Kromer, 1973). Neste ano os preços pularam de 5,25 dólares por bushel (um bushel vale aproximadamente $27 \mathrm{~kg}$ ) para 10,27 dólares por bushel. Tais preços podem ainda subir neste ano (Time Magazine, June 20, 1977: 40).

É pois, imperativo, explorar a possibilidade da produção de uma planta tão valiosa em áreas que necessitam desenvolvimento, nutrição melhorada e material de exportação. Áreas como são as várzeas da Amazônia, de solo relativamente rico, podem tornar-se em bons supridores desse grão, se certos problemas de agricultura mecanizada, de secagem e de armazenamento forem resolvidos por meio de pesquisas científicas.

Quinze variedades de elite, de soja, foram introduzidas pelos Estados Unidos, por meio do "International Soybean Program - INTSOY" e foram testadas nas várzeas do rio Solimões na localidade de Cacau Pirera, perto de Manaus, latitude de 3 graus 8 minutos sul e longitude de 60 graus e 2 minutos oeste.

As várzeas são áreas próximas do rio, que sofrem enchentes durante parte do ano, por 4 a 6 meses e são emersas por 6 a 8 meses (dependendo da altitude da área) .

O rio Solimões possui águas que carregam sedimentos bastante ricos, que săo depositados nessas áreas cada ano. Essas áreas são de grande importância agrícola e econômica e o seu potencial até agora está literalmente inexplorado.

Não conheço outros experimentos de soja, na Amazônia, feitos com metodologia científica rigorosa. Os objetivos foram: $1^{9}$ ) verificar se a produção de soja é possível nas condições do trópico úmido; $2^{p}$ ) descobrir se a produção de soja no Amazonas é economicamente possivel; $3^{9}$ ) selecionar os genótipos de soja para o Amazonas que sejam adaptados, insensíveis ao fotoperiodismo, de alta produção e resistentes a insetos e doenças.

(*) - Pesquisa realizada com auxilio da Polomazônia e CNPq (*) - Instituto Nacional de Pesquisas da Amazônia, Manaus. 


\section{MATERIAIS E MÉtodos}

O modelo experimental foi o de blocos totalmente casualizados, nos quais cada uma das 15 variedades foi replicada 4 vezes em canteiros de 4 linhas. O comprimento das linhas foi 5 metros e somente as duas linhas centrais foram utilizadas para coletas de dados, exceto no caso de nodulação em que 10 plantas foram arrancadas em 2 datas diferentes (ao tempo do florescimento e 3 semanas mais tarde) de duas das linhas exteriores dos canteiros.

Os dados foram coletados quanto a capacidade de produção, nodulação (número de nódulos e peso de nódulos secos a $70^{\circ} \mathrm{C}$ por 24 horas), número de dias requeridos para florescimento e para maturidade, altura da planta, número de vagens por planta (média de 10 plantas selecionadas ao acaso) ao peso de 100 sementes, acamamento, facilidade de danificar-se, qualidade de semente, resistência a doenças e insetos e porcentagem de proteínas e de óleos (análises feitas pela INTSOY, nos Esta. dos Unidos).

Aplicamos calcário, na taxa de 2 toneladas por hectare, enquanto $\mathrm{P}_{2} \mathrm{O}_{5}$ e $\mathrm{Kcl}$ foram adicionados na proporção de 35 e $66 \mathrm{~kg}$ por hectare. respectivamente.

O Rhizobium japonicum foi adicionado nas fileiras, imediatamente seguido do plantio de sementes. O experimento foi plantado em $16 / 10 / 75$. As sementes foram plantadas, coIhidas e debulhadas manualmente. A distância entre as fileiras foi $60 \mathrm{~cm}$ e entre as plantas foi $5 \mathrm{~cm}$. Usamos inseticida de tempos em tempos a fim de controlar um bezourinho não identificado no campo.

As variedades incluídas no experimento foram: Júpiter, Hampton 266A Hardee, Pelicano Melhorado, Cobb, Bossier, Davis, Tracy, Forrest, Columbus, Clark 63, Woodworth, Williams, Oriente (variedade, obtida localmente de um emigrante japonês, que substituiu uma das linhas provenientes dos Estados Unidos) e Semmes.

Os dadôs foram analisados em computador e com metodologia estatística adequada para análise de variância e regressão. O tes- te utilizado para comparaçōes de médias foi Tukey empregado para comparaçōes de média, apto em alguns casos onde usamos LSD.

A precipitação total recebida durante o período de crescimento foi de $918 \mathrm{~mm}$. O experimento não recebeu irrigação artificial.

\section{RESUlTADOS E DISCUSSÃo}

A Tabela 1 representa a colheita média, número de dias para florescimento e maturidade, número de nódulos, peso seco dos nódulos (baseado em 10 plantas), altura da planta, número de vagens por planta e peso de 100 sementes; os dados sobre acamamento, qualidade de sementes, porcentagem de proteína e óleo e índice de doenças, estão contidos na Tabela 2 .

A Tabela 1 mostra que a variedade que produziu a maior colheita foi a Júpiter com uma média de $4588 \mathrm{~kg}$ por hectare (em um relatório anterior este dado aparece como $4.890 \mathrm{~kg}$ por hectare (7); cerca de $1 / 4$ de uma réplica não germinou $e$ as parcelas perdidas foram adicionadas com base no resto das réplicas. Todavia, devido aos requisitos da análise estatistica, não foram incluídos nos cálculos desta publicação, ou seja, os dados aqui apresentados são os reais.

Esta colheita de Júpiter é estatística e significantemente maior do que todas as outras variedades testadas. As variedades Williams. Hardee, Pelicano Melhorado e Semmes produziram 2628, 2610, 2114 e $2050 \mathrm{~kg}$ por hectare

A colheita média de soja nos Estados Unidos e Brasil tem sido relatada como $2100 \mathrm{~kg}$ $\mathrm{p} /$ hectare e $1023 \mathrm{~kg} \mathrm{p} /$ hectare, respectivamente (Litzenberger, 1974; Probst \& Judd, 1973). A colheita de Júpiter de $4588 \mathrm{~kg}$ é realmente fenomenal. Os resultados de nossas pesquisas foram substanciados, mais tarde, por relatórios de desempenho dessa variedade em outros paises tropicais e subtropicais.

No México o governo estabeleceu um certro para produção de Júpiter. Tanto no México como nas Guianas, foram feitas regras de exportação muito restritas para sementes de Júpiter a outros países (comunicação pessoal dos Ministérios da Agricultura e da HARTZ SEED CO., Arkansas, USA). 
TABELA 1 - Colheita (em quilos por hectare), n.॰ de dias até o florescimento, n.॰ de dias até a maturidade, n.॰ mé. dio de nódulos, peso médio dos nódulos secos (baseados nos nódulos encontrados em 10 plantas), altura da planta, n. ${ }^{\circ}$ de vagens p/planta, peso de 100 sementes, dados de 15 variedades de soja, plantadas na várzea do rio Solimöes, na região de Cacau-Pirera, durante o período agrícola 1975-76

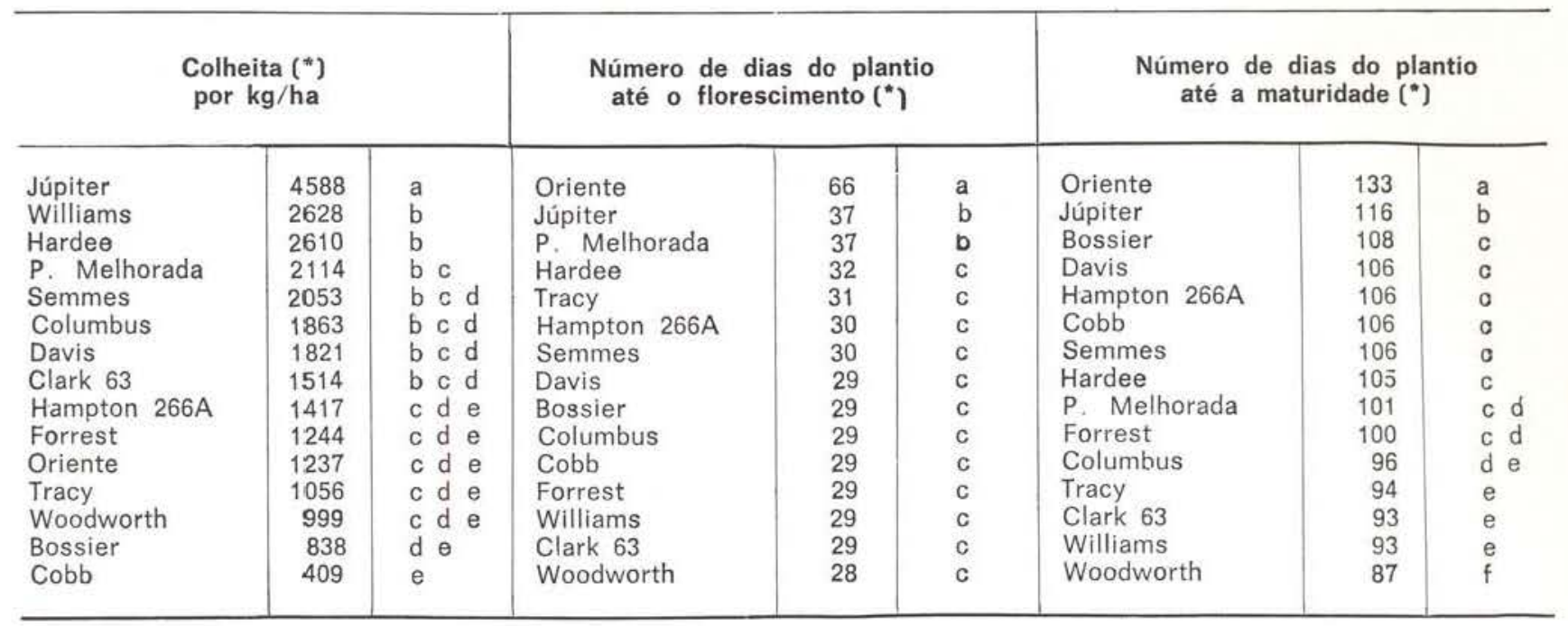

\begin{tabular}{|c|c|c|c|c|c|c|c|c|}
\hline \multicolumn{3}{|c|}{$\begin{array}{l}\text { N.॰ médio de nódulos baseado } \\
\text { no nódulos de } 10 \text { plantas }\left({ }^{*}\right)\end{array}$} & \multicolumn{3}{|c|}{$\begin{array}{l}\text { Peso seco de nódulos de dados ba- } \\
\text { seados em } 10 \text { plantas (em grama) (*) }\end{array}$} & \multicolumn{3}{|c|}{ Altura da planta e tecido (*) } \\
\hline Oriente & 314 & a & Júpiter & 3.6 & a & Oriente & 125 & a \\
\hline Júpiter & 260 & $a b$ & Oriente & 3.3 & $a b$ & P. Melnorada & 106 & $a$ \\
\hline Semmes & 224 & $a b$ & Semmes & 3.1 & $\mathrm{a} b$ & Júpiter & 85 & $\mathrm{~b}$ \\
\hline Hampton $266 \mathrm{~A}$ & 192 & b c & Bossier & 3.1 & $a b$ & Columbus & 71 & $\mathrm{c}$ \\
\hline Hardee & 190 & b c & Davis & 3.0 & $a b$ & Clark 63 & 66 & $\mathrm{c}$ \\
\hline P. Melhorada & 187 & b c & Hardee & 3.0 & $a b$ & Williams & 63 & c \\
\hline Forrest & 181 & $\mathrm{~b} c$ & Columbus & 2.8 & $a b$ & Woodworth & 56 & $c d$ \\
\hline Columbus & 167 & b c & Forrest & 2.8 & $a b$ & Hardee & 47 & d \\
\hline Bossier & 167 & b c & Hampton $266 \mathrm{~A}$ & 2.6 & $a b$ & Forrest & 42 & $d$ e $f$ \\
\hline Williams & 155 & b c & P. Melhorada & 2.3 & $a b$ & Davis & 36 & ef \\
\hline Clark 63 & 143 & b c & Cobb & 2.3 & $a b$ & Tracy & 35 & e f \\
\hline Davis & 132 & b c & Williams & 2.3 & $a b$ & Hampton 266A & 33 & e $f$ \\
\hline Cobb & 110 & c & Clark 63 & 2.3 & $a b$ & Semmes & 30 & e $f$ \\
\hline Woodworth & 110 & $\mathrm{c}$ & Tracy & 1.9 & b & Bossier & 29 & e \\
\hline Tracy & 104 & $\mathrm{c}$ & Woodworth & 1.9 & $\mathrm{~b}$ & Cobb & 26 & $\mathrm{f}$ \\
\hline
\end{tabular}

\begin{tabular}{|c|c|c|c|c|c|}
\hline \multicolumn{3}{|c|}{$\begin{array}{c}\text { Número de vagens por planta-s, baseado } \\
\text { em } 10 \text { plantas (") }\end{array}$} & \multicolumn{3}{|c|}{$\begin{array}{c}\text { Peso de } 100 \text { sementes, } \\
\text { em gramas (") }\end{array}$} \\
\hline $\begin{array}{l}\text { Oriente } \\
\text { P. Melhorada } \\
\text { Júpiter } \\
\text { Woodworth } \\
\text { Cobb } \\
\text { Clark } 63 \\
\text { Davis } \\
\text { Columbus } \\
\text { Williams } \\
\text { Hardee } \\
\text { Forrest } \\
\text { Hampton 266A } \\
\text { Semmes } \\
\text { Tracy } \\
\text { Bossier }\end{array}$ & $\begin{array}{r}188 \\
60 \\
57 \\
51 \\
50 \\
47 \\
40 \\
38 \\
36 \\
35 \\
35 \\
33 \\
32 \\
29 \\
29\end{array}$ & 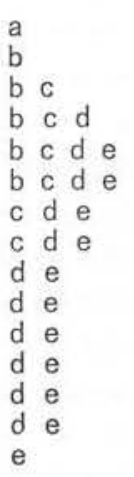 & $\begin{array}{l}\text { Hampton 266A } \\
\text { Júpiter } \\
\text { Tracy } \\
\text { Williams } \\
\text { Davis } \\
\text { Columbus } \\
\text { Hardee } \\
\text { Clark } 63 \\
\text { Semmes } \\
\text { Cobb } \\
\text { Bossier } \\
\text { Forrest } \\
\text { Woodworth } \\
\text { P. Melhorada } \\
\text { Oriente }\end{array}$ & $\begin{array}{l}23.3 \\
22.5 \\
21.3 \\
21.1 \\
20.9 \\
20.8 \\
20.6 \\
20.2 \\
19.8 \\
19.8 \\
19.4 \\
16.5 \\
16.4 \\
16.0 \\
14.3\end{array}$ & 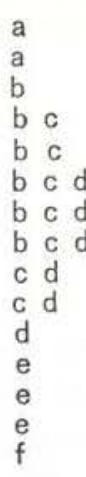 \\
\hline
\end{tabular}

(*) - Teste de Tuckey - as médias separadas por uma letra adicional diferem significantemente (p< 0.05 ), 
TABELA 2 - Dados médios sobre acamamento, qualidade de semente, porcentagem de proteínas, porcentagem de óleo, e indice de doenças de 15 variedades de soja, que cresceram na várzea do rio Solimões, na região de Cacau-Pirera, durante o período agricola 1975-76.

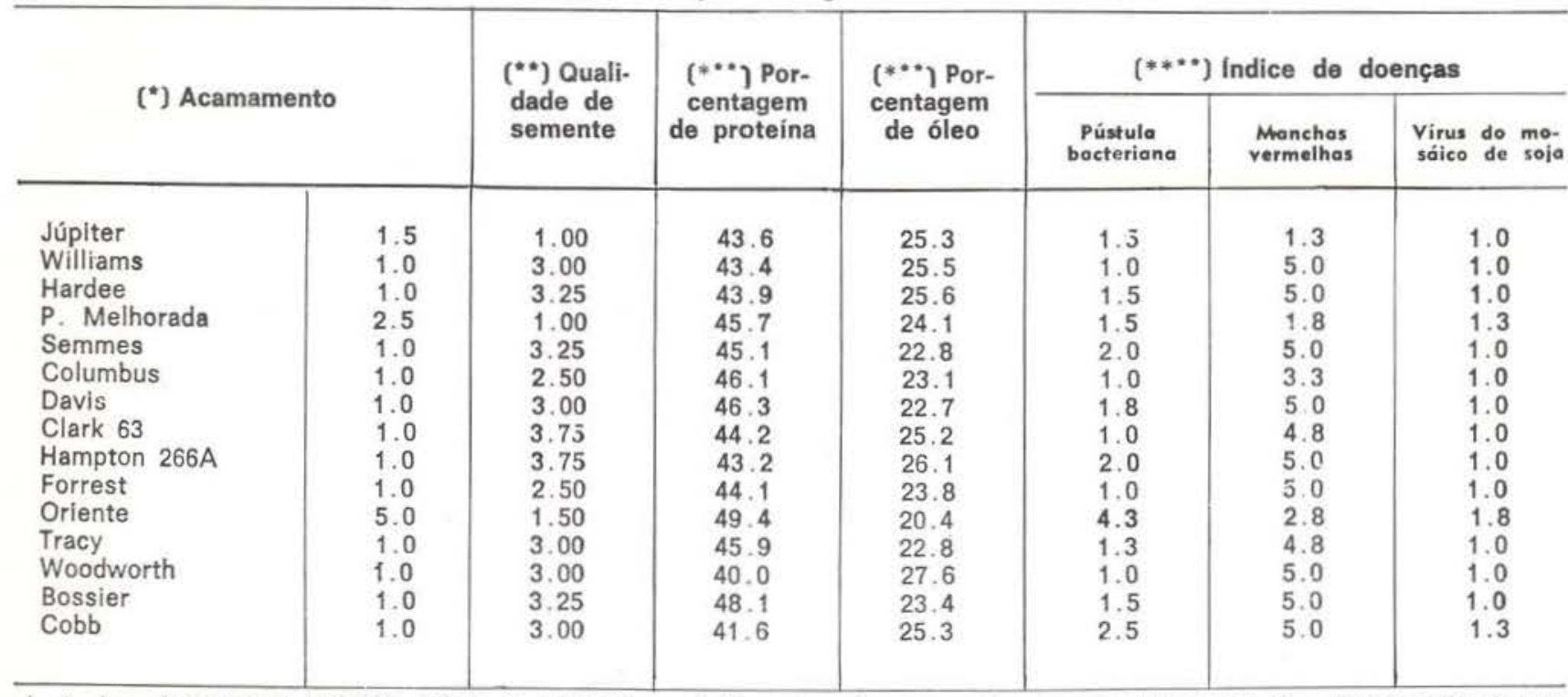

( * ) - Acomamento LSD $5 \%$, média de variedade $=0.30 . \quad 1=$ nāo acamo, $2=$ acama muito pouco, $3=$ acama moderadamente, $4=$ ocama bastante, $5=$ praticamente todas as plantas acamam.

( ...) - Qualidade: $1=$ excelente, $2=$ boa, $3=$ regular, $4=$ pobre, $5=$ muito pobre. $5 \%$ LSD para média da qualidade da variedode $=0,79$.

(***) - Porcentogem de Proteina e óleo. Análise feito nos Estados Unidos, por amostras compostas de 4 réplicos, (por INTSOY).

$(* * *)$ - indice de doenços: $1=$ nenhum sintoma, $2=$ sintomos muito leves, muito poucos plantas afetados: $3=$ sintomas moderados, um considerável número de plantas ofetodas; $4=$ sintomas severos, ou a maioria dos plantas; $5=$ sintomas muito severos em quose todas as plantas ou sementes.

O Programa Internacional de Soja (INTSOY), testou 20 variedades de soja, incluindo Júpiter. em 90 experimentos em 33 países durante o ano de 1973. A colheita de soja no Caldeirão foi a maior entre todas as localidades em que esta variedade foi testada (Whigham, 1974).

Em 1971 a colheita mais alta anotada nas Guianas foi a de Júpiter: $2359 \mathrm{~kg} \mathrm{p} /$ hectare com aplicaçōes de $123 \mathrm{~kg}$ de $\mathrm{P}_{2} \mathrm{O}_{5}, 269 \mathrm{~kg}$ de $\mathrm{K}_{2} \mathrm{O}, 17 \mathrm{~kg}$ de $\mathrm{N}, 18 \mathrm{~kg}$ de $\mathrm{MgO}$ e $17 \mathrm{~kg}$ de elementos menores por hectare (Kuell, 1972). Aplicamos somente $\mathrm{P}_{2} \mathrm{O}_{5}$ e $\mathrm{Kcl}$ na quantidade de $35 \mathrm{~kg}$ e $66 \mathrm{~kg} \mathrm{p} /$ hectare. Com a mesma proporção de fertilização, a Júpiter produziu 1099, 1867 e 723 quilos por hectare em Sri Lanka, Porto Rico e Indonésia em 1973 (Whigham, 1974). A mais alta colheita de Júpiter registrada nos experimentos INTSOY foi 3457 quilos por hectare em Gannoruwa em Sri Lanka (Whigham, 1974).

A variedade Oriente diferiu significantemente de todas as outras variedades no número de dias rêqueridos para florescer e maturar: 66 e 133 dias, respectivamente. Esta variedade pode ser uma fonte excelente de ge- nes para insensitividade ao fotoperiodismo nos programas de melhoramentos da Amazônia. As variedades Júpiter e Pelicano Melhorado requerem 37 dias para o florescimento e $116 \mathrm{e}$ 101 para a maturidade, respectivamente. Estas variedades diferiram estatisticamente de todas as outras, no tempo necessário para florescer, indicando excelente insensibilidade fotoperiódica que, sem dúvida alguma, teria uso prático nos programas de melhoramentos. Nas várzeas, talvez seja preferivel termos uma insensibilidade ao fotoperiodismo moderada do que uma insensibilidade fotoperiódica extrema, como de Oriente, porque nos nossos experimentos as variedades muito tardias acamaram excessivamente e săo relativamen. te mais susceptíveis à deteorização da qualidade devido às doenças. Essas observações não valem para terra firme (que são as terras não atingidas regularmente pelas enchentes), onde a situação é completamente diferente nesse respeito.

As variedades Oriente, Júpiter, Semmes, tiveram número maior e um peso seco dos nódulos, a saber: $314,260,224$ em 10 plantas 
e 3,$3 ; 3,6 ; 3,1$ gramas de nódulos secos por 10 plantas. Em geral a nodulação foi excelente neste experimento.

As variedades Oriente e Pelicano Melhorado cresceram até uma altura de $125 \mathrm{~cm}$ e $106 \mathrm{~cm}$, respectivamente, no que diferiu de todas as outras variedades, significantemente. A variedade Oriente acamou bastante devido ao seu peso excessivo; a variedade Júpiter demonstrou uma altura média de $85 \mathrm{~cm}$, no que ambas diferiram significantemente de todo 0 resto das outras variedades.

Oriente teve o maior número de vagens $\mathrm{p} /$ planta (188) seguida pelas variedades Pelicano Melhorada, Júpiter, Woodworth, Cobb, Clark 63, Davis e Columbus com 60, 57, 51, 50, 47,40 e 38 vagens p/planta, respectivamente. $A$ variedade Oriente diferiu significamente de todas as demais, todavia, Pelicano Melhorado e Júpiter também tiveram um número maior de vagens $p /$ planta, estatisticamente diferente de Williams, Hardee, Forrest, Hampton, Semmes, Tracy e Bossier. A amplitude das variedades foi de 23,3 gramas (peso de $100 \mathrm{se}$ mentes) no Hampton 266A a até 14,3 gramas na variedade Oriente. O peso de 100 sementes de Júpiter foi 22,5 gramas, que não foi estatisticamente diferente de Hampton 266A mas diferiu de todas as outras variedades. Forrest Woodworth e Pelicano Melhorado, com 16,5: 16,4 e 16 gramas por peso de 100 sementes, formavam uma classe diferente das demais, estatisticamente.

A Tabela 2 mostra os dados sobre acabamento, qualidade de sementes, porcentagem de proteína e óleo e indice de doenças. A maioria das variedades tiveram porte ereto, sem qualquer acamamento ou estrago na planta. A variedade Oriente acamou de maneira bastante séria com quase todas as plantas completamente caídas no campo. Umas poucas plantas de Júpiter foram também levemente curvadas, no caso de Pelicano Melhorada umas poucas plantas também foram inclinadas. As variedades Júpiter e Pelicano tiveram sementes de excelente qualidade. Essas duas variedades mostraram um grau de resistência extraordinário às condições de climas desfavoráveis que prevaleceram ao tempo da colheita. As sementes dessas variedades mantiveram qualidade muito boa, não obstante a umidade e a precipitação de chuvas terem sido excessivas. A qualidade das sementes na maioria das outras variedades foi drasticamente reduzida nestas condiçōes. Muitas variedades mostraram porcentagem excelente de proteína e óelo nas suas sementes. Júpiter, Pelicano Melhorada, Williams, Hardee e Semmes, mostraram um equilibrio muito bom na porcentagem de proteína e óleo. Em geral, após um certo pico, essas duas qualidades săo correlacionadas negativamente. A variedade Oriente teve a mais alta percentagem de proteína $(49,4)$ e ao mesmo tempo a menor de óleo $(20,4 \%)$.

Verificamos, por meio de correlação de regressão, executados nos dados que fizemos experimentalmente, que existe uma correlação significativa entre colheita e peso de nódulos secos, altura da planta, $n .^{\circ}$ de vagens $p /$ planta, peso de 100 sementes. Portanto, as seguintes equações de previsões para a colheita foram desenvolvidas: $Y=-3927,63+375,152$ $\left(X_{1}\right)+32,7338\left(X_{2}\right)-13,8826\left(X_{3}\right)+180,973$ $\left(\mathrm{X}_{4}\right)$, onde :

$$
\begin{aligned}
& \mathrm{Y}=\text { Produção em quilos } \mathrm{p} / \text { hectare } \\
& \mathrm{X}_{1}=\text { Peso seco de nódulos em gramas (ba- } \\
& \quad \text { seado em } 10 \text { plantas) } \\
& \mathrm{X}_{2} \text { - Altura da planta em centimetros } \\
& \mathrm{X}_{3}=\mathrm{n}^{\circ} \text { de vagens } \mathrm{p} / \text { planta } \\
& \mathrm{X}_{4} \text { - Peso de } 100 \text { sementes em gramas. }
\end{aligned}
$$

Somente três doenças foram observadas neste experimento; isto é, a Pústula Bacteriana, causada por Xanthomonas phaseoli variedade sojensis, a Mancha Vermelha, causada pelo fungo Cercospopra kikuchii, e o Virus do Mosáico da Soja (SMV). As variedades, Júpiter e Pelicano Melhorada, mostraram grande resistência e todas essas doenças, conforme pode-se observar pelas taxas que registramos na Tabela 2. A variedade Oriente toi muito susceptível à Pústula Bacteriana; a incidência do Vírus do Mosáico da Soja foi negligivel em geral. Sem dúvida, o problema mais sério foi o da Mancha Vermelha das sementes. A maioria das variedades foram muito susceptiveis a esse fungo especialmente em condições de alta umidade e excessiva precipitação, como ocorreu na época da colheita. Júpiter e P. Melhorada mostraram resistência muito boa a esta doença nessas condições. 
Nenhum problema de infestação por nematóides foi observado nestes experimentos de várzea. Isto pode ser explicado devido ao fato de que as várzeas ficam alagadas por vários meses durante o ano e, portanto, têm uma medida que promove o controle natural desses parasitas.

O dano por inseto também foi mínimo. Um besourinho não identificado foi controlado muito bem por pulverizaçăo com Malathion e Azodrin. Os resultados dos experimentos subseqüentes substanciaram solidamente nossas observações originais (resultados que serão publicados em breve). Podemos prever, a partir dos nossos experimentos, alguns problemas que aparecerão, em produção em larga escala nas várzeas do Amazonas :

1.') Mecanização da produção - Algumas várzeas têm solo relativamente macio. Nesses casos os trabalhos agrícolas deverão ser feitos com maquináriạ pequena de tamanho pequeno ou médio;

2.) Colheita em periodo chuvoso - (a) experimentos com práticas culturais, como por exemplo, usando variedades que maturem mais cedo e plantando-as tão cedo quanto possível, de maneira que se possa colher dentro de um periodo seco: (b) uma outra possibilidade é o uso de tratores com pneus duplos: (c) modificaçōes na maquinária existente ou invenção de novas maquinárias pode, também, ser possivel, se mentes criativas forem atraidas a este problema;

3.) Secagem e armazenagem - Este problema pode ser resolvido com a introdução de secadores artificiais e construção de espaços para armazenamento adequado.

\section{SUMMARY}

Initial studies indicate that large scale soybean production in the relatively fertile and unexplored varzeas of Amazonia (areas near the river that are flooded part of the year which leaves a rich sediment on the land) may be highgly feasible if drying and storage facilities are made available and if certain other technical problems, e.g., mechanization of production and harvesting during the wet, rainy period (combining early maturing varieties with early time of planting to harvest within the dry period may be one solution) are solved by further experimentation.

Out of 15 varieties tested in this experiment five yielded more than $2000 \mathrm{~kg}$ per hectare. Jupiter yielded the highest amount of seeds, i.e., $4588 \mathrm{~kg}$ per hectare followed by Williams, Hardee, Improved Pelican, and Semmes with 2628, 2610, 2114, and 2053 $\mathrm{kg}$ per hectare respectively.

Jupiter required 37 days for flowering, 116 days for maturity, stood erect, had excellent nodulation, and excellent quality of seeds. Its seeds contained 43.6 percent protein and 25.3 percent oil.

Jupiter showed an amazing degree of resistance to diseases under the most unfavourable conditions of excessive rainfall and humidity under which its seeds also maintained their excellent quality. Improved Pelican also exhibited similar characteristics.

COWAN, J.C.

\section{BIBLIOGRAFIA CITADA}

1973 - Processing and products. In: Caldwell. B.E. ed. - Soybeans: improvement, production, and uses. American, Society of Agronomy. p. 619-656.

KUELL, HINSON

1972 - Jupiter: a new soybean variety for tropical latitudes. Florida Agri. Expt. Sta. Circular S-217.

Kromer, G.W.

1973 - World oil and protein situation. In: Caldwell, B.E. ed. - Soybeans: improvement, production, and uses. American Society of Agronomy. p. 573-586.

LITZENBERGER, S.C. ED.

1974 - Guide for field crops in the tropics and the subtropics. p. 179-186.

PROBST, A.H. \& JUDD, R.W

1973 - Origin, U.S. History, and development, and world distribution. In: Caldwell, B.E. ed. - Soybeans: improvement, production, and uses. American Society of agronomy. p. 1-12.

RAHMAN, F

1976 - A proposal for the introduction of soybeans (Glycine $\max$ ) as an export cash-crop with superior productive and nutritional qualities for the local consumption in Amazonia. Unpubliched. Submitted to the Instituto Nacional de Pesquisas da Amazônia (INPA) on February 27, 1976.

SOYBean Magic...

The Story of Soybean processsing. Leaflet by - National Soybean Processors Association of the U.S.A.

Time Magazine

Economy and business. p. 40 , june 20 1977.

WнIGнам, D.K.

1974 - International variety trials. Proceedings of the workshop on Soybeans for Tropical and Subtropical conditions. p. 20-37. 